\title{
Effect of high parity on occurrence of some fetal growth indices: a cohort study
}

This article was published in the following Dove Press journal:

International Journal of Women's Health

2 July 2012

Number of times this article has been viewed

\author{
Yahya M Al-Farsi ${ }^{1,2}$ \\ Daniel R Brooks ${ }^{2}$ \\ Martha MWerler ${ }^{2}$ \\ Howard J Cabral ${ }^{2}$ \\ Mohammed A Al-Shafaee' \\ Henk C Wallenburg ${ }^{3}$ \\ 'Department of Family Medicine and \\ Public Health, College of Medicine \\ and Health Sciences, Sultan Qaboos \\ University, Muscat, Sultanate of Oman; \\ ${ }^{2}$ Department of Epidemiology, School \\ of Public Health, Boston University, \\ Boston, MA, USA; ${ }^{3}$ Department of \\ Obstetrics and Gynecology, College \\ of Medicine and Health Sciences, \\ Sultan Qaboos University, Muscat, \\ Sultanate of Oman
}

Correspondence: YM Al-Farsi Department of Family Medicine and Public Health, College of Medicine and Health Sciences, Sultan Qaboos University, PO Box 35, I23 Al-Khoudh, Sultanate of Oman

$\mathrm{Tel}+9682414 \quad$ I 102

Fax+968-244I 3300

Email ymfarsi@squ.edu.om
Abstract: The objective of this retrospective cohort study was to explore the potential causal relation between parity and fetal growth indices, including low birth weight (LBW), macrosomia, and prematurity. The study was nested on a community trial in a city in Oman. The study analyzed 1939 pregnancies among 479 participants. Of these, 944 pregnancies $(48.7 \%)$ were high parity $(\geq 5)$. Obtained newborns with outcomes of interest were as follows: 191 LBW, 34 macrosomic, and 69 premature. Associations were measured using multilevel logistic regression modeling. Compared to low parity (LP, defined as $<5$ ), high parity was found to be associated with less risk of LBW (relative risk $[\mathrm{RR}]=0.76$; 95\% confidence interval [CI]: 0.44-1.1) and prematurity $(\mathrm{RR}=0.82 ; 95 \% \mathrm{CI}: 0.54-1.27)$, but greater risk of macrosomia $(\mathrm{RR}=1.8 ; 95 \% \mathrm{CI}: 1.2-2.4)$. This study provides evidence that with increasing parity, risks of LBW and prematurity decrease, while risk of macrosomia increases.

Keywords: parity, fetal growth, low birth weight, macrosomia, prematurity, Oman

\section{Introduction}

Abnormal fetal growth is associated with multiple adverse outcomes for the mother and the newborn, such as perinatal morbidities, developmental disorders, and learning disabilities. ${ }^{1}$ Abnormal fetal growth is usually assessed through multiple indices, including low birth weight (LBW), small size relative to gestational age, macrosomia, and prematurity.

High parity (HP), defined as having $\geq 5$ pregnancies of $\geq 20$ weeks of gestation, is among various risk factors which have been hypothesized for fetal growth abnormalities. ${ }^{2}$ Although HP has been recognized to be a potential risk factor for abnormal fetal growth, the exact etiological mechanism is not well understood. Studies investigating whether increasing parity has an adverse effect on fetal growth have yielded inconsistent results. Some studies have confirmed a negative effect evidenced by LBW and prematurity, ${ }^{3-5}$ while others revealed no association or even an increased frequency of macrosomia. ${ }^{6,7}$ This inconsistency has been attributed, among other factors, to inadequate sampling of high parity women, especially in developed countries, as well as failure to adequately adjust for strong confounders.

HP is rarely seen in developed countries due to the widespread use of contraceptive measures and family planning. Nonetheless, it is still common in many developing countries, especially in the Arab world where a cultural preference for larger families is still prevalent. ${ }^{2}$ Oman, an Arab country characterized by an especially high birthrate, ${ }^{8}$ was accordingly selected as an ideal location for a new study that aims to investigate 
the association between high parity and three fetal growth indices: LBW, prematurity, and macrosomia.

\section{Materials and methods}

This population-based retrospective cohort study was conducted from January 2006 to August 2006 in Bidbid, a city located about 30 kilometers west of Muscat, the capital of Oman. Bidbid was also the catchment population for an ongoing community trial entitled "Delaying the Development of Diabetes Mellitus Type 2 in Oman," also known as the "AMAL study." This community trial, which was conducted from 2004 through 2008, aimed to estimate the prevalence of prediabetes among adults in Bidbid and to apply appropriate interventions to prevent the occurrence of diabetes. The study was approved by the Medical Research and Ethics Committee at Sultan Qaboos University.

The target population for the present study consisted of 541 parous women who had previously enrolled in the AMAL study. Of those women, 532 consented to participate in our study, yielding a response rate of $98.3 \%$. The enrolled women had a total of 1,939 singleton pregnancies during the duration of the study. Miscarriages, twin pregnancies, and pregnancies of less than 20 weeks of gestation were excluded.

Information about parity, LBW, and associated factors was obtained from Maternal Health Cards which recorded salient information for each pregnancy, such as sociodemographic data, prepregnancy risk factors, obstetric and medical history, clinical findings at each antenatal visit, investigations, details of delivery, and postnatal findings.

Parity was defined both dichotomously $(<5, \geq 5)$ and by multiple categories $(1,2-3,4-5,6-7,8-9$, and $\geq 10)$. LBW was defined as $<2500 \mathrm{~g}$. Individual pregnancies, rather than women, were the unit of analysis for this study, with the cumulative incidence of LBW reported per 100 pregnancies. Outcomes of interest were: (1) LBW (defined as <2500 g). (2) macrosomia (defined as $>4000 \mathrm{~g}$ ), and (3) prematurity (defined as $<37$ weeks of gestation).

Multilevel logistic regression (MLLR) analysis was used to assess the effect of parity on the aforementioned outcomes. Multilevel regression modeling was preferred over conventional regression due to its ability to adjust for the dependency that exists among same-woman pregnancies. ${ }^{9}$ Two series of MLLR were conducted in order to separately assess both dichotomous parity and categorical parity. Two sets of subanalyses were conducted within each series: a crude model and an adjusted model. In the crude model, parity was treated as the only predictor of occurrence of LBW. In the adjusted model, adjustment was made for the following confounders: maternal age, educational status of mothers, family income, past history of LBW, and year of delivery. Similar crude and adjusted models were generated for the other outcomes: prematurity and macrosomia. The same set of confounders was considered in all adjusted models. The trend of association between categorical parity and outcomes was tested using the Cochran-Armitage test for trend, and a cutoff value for statistical significance was taken at $P<0.05$.

Chi-square analyses were used to evaluate the statistical significance of differences among proportions of categorical data. The nonparametric Fisher's exact test (two-tailed) replaced the Chi-square test in cases of small sample size where the expected frequency was less than 5 in any of the cells in $2 \times 2$ tables. All statistical analyses were performed using SAS software (version 9.1; SAS Institute, Cary, NC).

\section{Results}

A total of 1939 pregnancies were enumerated of which 944 (48.7\%) were HP and 995 (51.3\%) were low parity (LP). Table 1 compares LP and HP pregnancies with respect to important baseline characteristics existing at the beginning of each pregnancy. Compared to LP pregnancies, HP pregnancies

Table I Sociodemographic and selected antenatal characteristics of pregnancies by parity status

\begin{tabular}{|c|c|c|}
\hline & $\begin{array}{l}\text { LP pregnancies } \\
(\mathrm{n}=995)\end{array}$ & $\begin{array}{l}\text { HP pregnancies } \\
(\mathrm{n}=944)\end{array}$ \\
\hline Age (mean) & $23.9(3.5)$ & $32.1(5.7)$ \\
\hline Gestational age (mean) & $38.4(0.6)$ & $39.3(0.7)$ \\
\hline \multicolumn{2}{|l|}{ in months (mean) } & $27.0(2.0)$ \\
\hline BMI (average) & $24.3(1.4)$ & $27.2(1.9)$ \\
\hline \multicolumn{3}{|l|}{ Education } \\
\hline Illiterate & $194(19.5)$ & $573(60.7)$ \\
\hline 6 th grade & $342(34.4)$ & $280(28.2)$ \\
\hline 9th grade & $194(19.5)$ & $55(5.8)$ \\
\hline 12th grade & I7I (17.2) & $24(2.5)$ \\
\hline College or beyond & $94(9.4)$ & $12(1.3)$ \\
\hline \multicolumn{3}{|c|}{ Monthly family income (in Omani Rials) } \\
\hline Low $(<200)$ & $415(4 I .7)$ & $240(24.1)$ \\
\hline Middle (200 to 500 ) & $442(44.2)$ & $531(56.3)$ \\
\hline High-middle (500 to I000) & $104(10.5)$ & $146(15.5)$ \\
\hline High $(>1000)$ & $34(3.4)$ & $27(2.7)$ \\
\hline \multicolumn{3}{|l|}{ Year of delivery } \\
\hline Before 1990 & $112(11.3)$ & $122(12.9)$ \\
\hline 1990 to 1999 & $54 \mid(54.4)$ & $573(60.7)$ \\
\hline 2000 and later & $342(34.4)$ & $249(26.4)$ \\
\hline History of LBW & $26(2.6)$ & $23(2.4)$ \\
\hline History of gestational diabetes & $64(6.4)$ & $152(16.1)$ \\
\hline
\end{tabular}

Note: Figures in parentheses are percentages or standard deviations.

Abbreviations: LP, low parity; HP, high parity; BMI, body mass index; LBW, low birth weight. 
were shown to be associated with the following maternal characteristics: older age, higher body mass index (BMI), illiteracy, higher family income, and increased frequency of both LBW and gestational diabetes mellitus. Gestational duration did not vary significantly between LP and HP pregnancies.

Table 2 shows the incidence of outcomes of interest for each category of parity. Frequencies of recorded newborns with disease outcomes of interest were as follows: $191 \mathrm{LBW}$, 69 prematurity, and 34 macrosomia. Fewer cases of LBW ( 80 vs 111 ) and prematurity (28 vs 41 ) were documented among HP pregnancies as compared to LP pregnancies. Thus, the incidence of LBW among HP pregnancies (8.5 per 100 pregnancies; 80/944) was lower than among LP pregnancies (11.1 per 100 pregnancies; 111/995). The difference in incidence risk of LBW was not statistically significant $(P=0.06)$. HP pregnancies also had a lower incidence of prematurity (3.0 per 100 pregnancies; 28/944) than LP pregnancies (4.1 per 100 pregnancies; 41/995), and the difference was not statistically significant $(P=0.26)$. More macrosomia cases occurred among HP pregnancies (22 vs 12), yielding a higher incidence of macrosomia among HP pregnancies (2.3 per 100 pregnancies; 22/944) than LP pregnancies (1.2 per 100 pregnancies; 12/995), but the difference was not statistically significant $(P=0.61)$.

Table 3 shows the results of adjusted MLLR modeling. HP pregnancies exhibited a $24 \%$ reduction in the risk of LBW (relative risk $[R R]=0.76 ; 95 \%$ confidence interval [CI]: $0.44-1.1$ ) and an $18 \%$ reduction in risk of prematurity $(\mathrm{RR}=0.82 ; 95 \% \mathrm{CI}: 0.54-1.27)$ relative to LP pregnancies. Nonetheless, these observed reductions in risks were not statistically significant. Additionally, the risk of having a macrosomic baby was higher among HP pregnancies $(\mathrm{RR}=1.8 ; 95 \% \mathrm{CI}: 1.2-2.4)$. Using parity of $2-3$ as the reference category, the adjusted MLLR model revealed a

Table 2 Fetal growth indices by parity status

\begin{tabular}{|c|c|c|c|c|}
\hline & \multirow[t]{2}{*}{ Total } & \multicolumn{3}{|l|}{ Cases (\%) } \\
\hline & & $\begin{array}{l}\text { LBW } \\
(n=191)\end{array}$ & $\begin{array}{l}\text { Macrosomia } \\
(n=34)\end{array}$ & $\begin{array}{l}\text { Prematurity } \\
(n=69)\end{array}$ \\
\hline \multicolumn{5}{|c|}{ Dichotomous parity } \\
\hline $\mathrm{LP}(<5)$ & 995 & II I (58. I) & $12(35.3)$ & $4 \mid(59.4)$ \\
\hline $\mathrm{HP}(\geq 5)$ & 944 & $80(41.9)$ & $22(64.7)$ & $28(40.6)$ \\
\hline \multicolumn{5}{|c|}{ Categorical parity } \\
\hline I & 276 & $44(23.0)$ & I (2.9) & $19(27.5)$ \\
\hline $2-3$ & 505 & $52(27.2)$ & $9(26.5)$ & $16(23.2)$ \\
\hline $4-5$ & 397 & $29(15.2)$ & $10(29.4)$ & $14(20.3)$ \\
\hline $6-7$ & 338 & $31(16.2)$ & $9(26.5)$ & $13(18.8)$ \\
\hline $8-9$ & 239 & $23(12.0)$ & $3(8.8)$ & $4(5.8)$ \\
\hline$\geq 10$ & 184 & $12(6.3)$ & $2(5.9)$ & $3(4.3)$ \\
\hline
\end{tabular}

Abbreviations: LBW, low birth weight; LP, low parity; HP, high parity.
Table 3 Adjusted risk ratios for fetal growth indices by parity status

\begin{tabular}{|c|c|c|c|}
\hline Parity & $\begin{array}{l}\text { LBW } \\
\text { RR }(95 \% \mathrm{Cl})\end{array}$ & $\begin{array}{l}\text { Macrosomia } \\
\text { RR }(95 \% \mathrm{Cl})\end{array}$ & $\begin{array}{l}\text { Prematurity } \\
\text { RR }(95 \% \mathrm{Cl})\end{array}$ \\
\hline \multicolumn{4}{|c|}{ Dichotomous } \\
\hline $\operatorname{LP}(<5)$ & 1.0 & 1.0 & 1.0 \\
\hline $\mathrm{HP}(\geq 5)$ & $0.76(0.44-I . I)$ & $1.8(1.2-2.4)$ & $0.82(0.54-1.27)$ \\
\hline \multicolumn{4}{|c|}{ Categorical } \\
\hline I & $1.91(1.18-2.55)$ & $0.2(0.02-1.8)$ & $1.47(1.08-2.21)$ \\
\hline $2-3$ & 1.0 & 1.0 & 1.0 \\
\hline $4-5$ & $0.56(0.32-1.13)$ & $1.4(0.9-3.2)$ & $0.93(0.45-1.36)$ \\
\hline $6-7$ & $0.75(0.37-1.59)$ & $1.5(1.3-4.8)$ & $0.79(0.42-1.39)$ \\
\hline $8-9$ & $0.82(0.49-1.69)$ & $1.3(0.3-3.3)$ & $0.69(0.39-1.23)$ \\
\hline$\geq 10$ & $0.45(0.22-1.27)$ & $1.4(0.2-3.5)$ & $0.62(0.3 I-2.10)$ \\
\hline
\end{tabular}

Note: The following factors were adjusted for in the adjusted regression models: age, education, family income, year of delivery, and past history of LBW.

Abbreviations: LBW, low birth weight; RR, relative risk; $\mathrm{Cl}, 95 \%$ confidence intervals; LP, low parity; HP, high parity.

preventive dose-response relation between parity and the risk of both LBW and prematurity (trend, $P=0.04$ ). The adjusted RR sequence also showed a correlation between increasing parity and elevated risk of macrosomia, but with a plateau trend rather than a dose-response relation (trend, $P=0.37$ ).

\section{Discussion}

This retrospective population-based cohort study explored whether parity has an effect on the occurrence of LBW, prematurity, and macrosomia. The results showed that higher parity was positively associated with macrosomia and negatively associated with both LBW and prematurity.

Primiparity was found to be associated with an increased risk of LBW compared to multiparity. The increased risk of LBW among primiparous women may be explained by the lower average age of primiparous women, which is known to be associated with greater risk of both prematurity and pre-eclampsia; the latter also necessitating delivery before term. ${ }^{10,11}$

For multiparous pregnancies, higher parity was found to be associated with a decreased risk of LBW in a negative doseresponse fashion. This finding may be explained by the association between higher parity and maternal hyperglycemia, which tends to result in higher birth weight. ${ }^{12}$ Although the overall trend suggested reduction in risk of LBW as parity increases, it is worth mentioning that the reduction in risk of LBW in each subcategory of parity was not statistically significant, and this might be attributed to statistical instability caused by a small category-specific sample size.

These results are in line with previous studies reporting that high parity is associated with a decreased risk of LBW and an increased risk of macrosomia. ${ }^{3,13-15}$ For example, a 
prospective cohort study of 1098 pregnancies in Finland found a steady increase in average birth weight in correlation with higher parity. ${ }^{12}$

Other studies have found high parity to be associated with an increased risk of LBW; ${ }^{3-5}$ however, at least some of these results have been attributed to placental complications such as atresia or abruption. Thus, their apparent disagreement with the present study's results might be due to the absence of this factor. Others reporting conflicting results have postulated that observed elevations of the risk of LBW were caused by the additional domestic workload undertaken by women, along with each additional child. ${ }^{16}$ We do not reach a similar conclusion, despite the fact that the majority of pregnancies included in the present study were among illiterate women from low- or middle-income families with extensive domestic responsibilities.

This study's use of prospectively documented data among a population with an overall prevalence of HP is one of its strengths. This feature substantially increased the statistical stability of the data notwithstanding the need to adjust for multiple confounders within smaller subcategories. A possible residual confounder is the nutritional status of the women, as sufficient information to adjust for this factor was not available.

With estimates as high as $27.6 \%$, Oman has the second highest annual incidence proportion of HP pregnancies in the world (after the United Arab Emirates), ${ }^{2}$ as well as the highest reported incidence proportion of extreme parity $(\geq 10)$ in the world $(11.3 \%) .{ }^{17}$

Several explanations have been proposed for these high figures, including limited use of contraceptive measures, cultural idealization of large family size, suboptimal female education, and shortcomings in the implementation of the national birth spacing policy.

Local attitudes towards - and limitations of - family planning are illustrated by a survey which estimated that the prevalence of contraceptive use among Omani women is only $12.7 \%$, and only $64.3 \%$ of users believed contraceptives were desirable. ${ }^{18}$ Another survey of Omani high school students reported that around $43 \%$ of boys and $20.8 \%$ of girls stated a preference to have six or more children in the future. ${ }^{19}$ This indicates that widespread HP is likely to remain the status quo, even among younger, more educated generations. Given such high rates of HP in Oman, it is especially important for the local medical community to understand its potential health impacts in order to provide better health services for multiparous women and their children.

In conclusion, this study provides evidence that high parity is associated with a lower risk of LBW and prematurity as well as a higher risk of macrosomia. These results could be usefully considered in designing effective national health policy programs aimed at improving the health of mothers and children in Oman and similar populations. These results can be used to address more targeted family planning programs at the local community level. For example, the observed increased risk of macrosomia can be used to educate women who are at risk of having macrosomic babies because of predisposing conditions such as diabetes mellitus.

These findings should not be interpreted in isolation from other potential consequences of high parity. Further studies are needed to explore, for example, the social and economic effects of larger nuclear family size on both mothers and their families.

\section{Acknowledgments}

The authors would like to thank Dr Kamlesh Bhargava, principal investigator of the AMAL Study, and the AMAL Study research team for their extensive logistical support, without which this work would not have been possible.

\section{Disclosure}

The authors declare no potential conflicts of interest.

\section{References}

1. Ashdown-Lambert JR. A review of low birth weight: predictors, precursors and morbidity outcomes. J R Soc Health. 2005;125(2):76-83.

2. Aliyu MH, Jolly PE, Ehiri JE, Salihu HM. High parity and adverse birth outcomes: exploring the maze. Birth. 2005;32(1):45-59.

3. Aliyu MH, Salihu HM, Keith LG, Ehiri JE, Islam MA, Jolly PE. High parity and fetal morbidity outcomes. Obstet Gynecol. 2005;105(5 Pt 1): 1045-1051.

4. Ozumba BC, Igwegbe AO. The challenge of grandmultiparity in Nigerian obstetric practice. Int J Gynaecol Obstet. 1992;37:259-264.

5. Seidman DS, Armon Y, Roll D. Grand multiparity: an obstetric or neonatal risk factor? Am J Obstet Gynecol. 1988;158:1034-1039.

6. Eidelman AI, Kamar R, Schimmel MS, Baron E. The grand multipara: is she still at risk? Am J Obstet Gynecol. 1988;158:389-392.

7. Sipila P, von Wendt L, Hartikainen-Sorri AL. The grand multipara - still an obstetrical challenge? Arch Gynecol Obstet. 1990;247:187-195.

8. Sultanate of Oman Ministry of National Economy. Human Development Report 2003. Muscat, Oman: Ministry of National Economy; 2003. Available from http://www.moneoman.gov.om/book/hdr03/Final_en/ en/ind_1.pdf. Accessed May 6, 2012.

9. Diez Roux AV. The study of group-level factors in epidemiology: rethinking variables, study designs, and analytical approaches. Epidemiol Rev. 2004;26:104-111.

10. Bánhidy F, Acs N, Puhó EH, Czeizel AE. Pregnancy complications and birth outcomes of pregnant women with urinary tract infections and related drug treatments. Scand J Infect Dis. 2007;39(5):390-397.

11. Martius JA, Steck T, Oehler MK, Wulf KH. Risk factors associated with preterm $(<37+0$ weeks $)$ and early preterm birth $(<32+0$ weeks): univariate and multivariate analysis of 106345 singleton births from the 1994 statewide perinatal survey of Bavaria. Eur J Obstet Gynecol Reprod Biol. 1998;80(2):183-189.

12. Juntunen KS, Laara EM, Kauppila AJ. Grand multiparity and birth weight. Obstet Gynecol. 1997;90:495-499. 
13. Kumari AS, Badrinath P. Extreme grandmultiparity: is it an obstetric risk factor? Eur J Obstet Gynecol Reprod Biol. 2002;101:22-25.

14. Toohey J, Keegan JR, Morgan M, et al. The dangerous multipara: Fact or fiction? Am J Obstet Gynecol. 1995;172:683-686.

15. Hughes PF, Morrison J. Grand multiparity - not to be feared? An analysis of grand multiparous women receiving modern antenatal care. Int J Gynaecol Obstet. 1994;44:21-31.

16. Schram ELR. The problem of the grand multipara. Am J Obstet Gynecol. 1954;67:253-262.

17. Ministry of Health. Sultanate of Oman. Annual Statistics Report 2007. Muscat, Oman: Ministry of Health; 2007. Available from: http://www. moh.gov.om. Accessed February 4, 2009.
18. Ministry of Health. Sultanate of Oman. National Survey on Knowledge, Attitude and Practice Towards Birth Spacing, 1994. Available from: http://www.moh.gov.om. Accessed February 15, 2009.

19. Ministry of Health. Sultanate of Oman. Towards better understanding of adolescents. KAP survey for secondary school children in public health and reproductive health by a self-administered questionnaire, 2001. Available from: http://www.moh.gov.om. Accessed February 15, 2009.

International Journal of Women's Health

\section{Publish your work in this journal}

The International Journal of Women's Health is an international, peerreviewed open-access journal publishing original research, reports, reviews and commentaries on all aspects of women's healthcare including gynecology, obstetrics, and breast cancer. Subject areas include Chronic conditions (migraine headaches, arthritis, osteoporosis);

\section{Dovepress}

Endocrine and autoimmune syndromes; Sexual and reproductive health; Psychological and psychosocial conditions. The manuscript management system is completely online and includes a very quick and fair peer-review system. Visit http://www.dovepress.com/ testimonials.php to read real quotes from published authors.

Submit your manuscript here: http://www.dovepress.com/international-journal-of-womens-health-journal 